J. MED. MICROBIOL.-VOL. 19 (1985) 35-43

(C) 1985 The Pathological Society of Great Britain and Ireland

\title{
FIMBRIAL AND NON-FIMBRIAL HAEMAGGLUTININS IN ENTEROBACTER AEROGENES
}

\author{
R. A. Adegbola and D. C. Old \\ Department of Medical Microbiology, University of Dundee Medical School, \\ Ninewells Hospital, Dundee DDI 9SY
}

\begin{abstract}
SUMMARY. Ten strains of Enterobacter aerogenes were examined for their ability to produce haemagglutinins and fimbriae. Nine strains formed a mannose-sensitive (MS) haemagglutinin associated with thin $(4 \mathrm{~nm})$ non-channelled fimbriae. These thin fimbriae of E. aerogenes were antigenically different from the thin fimbriae of other fimbriate strains of Enterobacter and Klebsiella and probably represent a new kind of fimbria not previously described in Enterobacteriaceae. Eight of these same nine strains also formed a non-fimbrial mannose-resistant, proteus-like (MR/P) haemagglutinin. The formation of thin fimbriae associated with MS haemagglutinin and of non-fimbrial MR/P haemagglutinin are properties not associated with other strains of Enterobacter and Klebsiella.

$E$. aerogenes strain NCIB11460 was unusual among the strains examined in this series in that it alone produced mannose-resistant, Klebsiella-like (MR/K) haemagglutinin and type-3 fimbriae which, as judged by immunoelectronmicroscopy, were antigenically like those of type-3 fimbriate Klebsiella strains. The identifying characters of this exceptional strain of E. aerogenes are discussed in detail.

All ten strains also produced thick fimbriae which by immunoelectronmiscroscopy behaved like the type-1 fimbriae of Klebsiella strains. However, correlation between their presence and the production of MS haemagglutinin in $E$. aerogenes was not established. The findings are discussed in the light of the present difficult taxonomic status of $E$. aerogenes within the tribe Klebsielleae.
\end{abstract}

\section{INTRODUCTION}

Among strains of Enterobacter of different species examined in previous studies (Adegbola and Old, 1983; Old and Adegbola, 1984), correlations were established (i) between the production of mannose-sensitive haemagglutinin (MS-HA) and type-1 fimbriae and (ii) between the production of mannose-resistant, Klebsiella-like haemagglutinin (MR/K-HA) and type-3 fimbriae. However, no similar correlations were established between production of haemagglutinins and fimbriae among strains 
of $E$. aerogenes a species which, it has been proposed, should be transferred to the genus Klebsiella as K. mobilis (Bascomb et al., 1971; Izard et al., 1980).

From a detailed study of ten strains of $E$. aerogenes we present findings which suggest that the fimbriae and haemagglutinins of that species are not like those of other species of Enterobacter and Klebsiella.

\section{MATERIALS AND METHODS}

Bacterial strains. The sources of the strains of E. aerogenes are given in table I. The identity of each strain was confirmed by conventional tests (Edwards and Ewing, 1972) and in tests with API 20E kits (API Laboratory Products Ltd, Basingstoke, Hampshire). Thus, each strain gave a profile (5105773 for strain PADG $2.77 ; 5305773$ for all others) which afforded very good identification as E. aerogenes.

Media and culture methods. The media and growth conditions have been described before (Adegbola and Old, 1982 and 1983).

Erythrocytes and haemagglutination tests. The preparation of erythrocytes of species of fowl $(\mathrm{F})$, guinea pig $(\mathrm{G})$, horse $(\mathrm{H})$, man, group $\mathrm{O}(\mathrm{M})$, ox $(\mathrm{O})$, pig $(\mathrm{P})$ and sheep $(\mathrm{S})$, the tannic acid-treatment of erythrocytes and the performance of the haemagglutination tests followed previously described methods (Duguid, 1959; Adegbola and Old, 1982 and 1983). The characterisations of MS-HA, MR/K-HA and the mannose-resistant, proteus-like (MR/P) haemagglutinin have been described in full elsewhere (Duguid and Old, 1980; Old and Adegbola, 1982).

Preparation of fimbrial antisera. Fimbrial antisera were prepared in rabbits by the method of Adegbola and Old (1982) against: $K$. pneumoniae ss. aerogenes strain K55/1 which produces type-1 (thick) fimbriae only (Adegbola and Old, 1982); K. oxytoca strain K 70/1 which produces type-3 (thin) fimbriae only (Adegbola and Old, 1982); E. aerogenes strain NCIB1 1460 which produces type-3 fimbriae only (Old and Adegbola, 1984); E. aerogenes strains NCTC9735 and NCTC10336 which produce an MS-HA associated with thin fimbriae (vide infra). Each antiserum was made monospecific for its stated fimbrial type by a series of absorptions to remove $\mathrm{O}$ and, where appropriate, $\mathrm{H}$ antibodies.

TABLE I

Haemagglutinins and fimbriae produced by strains of E. aerogenes

\begin{tabular}{|c|c|c|c|c|c|}
\hline \multirow{3}{*}{$\begin{array}{l}\text { Strain no. } \\
\text { and } \\
\text { source* }\end{array}$} & \multicolumn{5}{|c|}{ Production of } \\
\hline & \multicolumn{3}{|c|}{ Haemagglutinins $\dagger$} & \multicolumn{2}{|c|}{ Fimbriae } \\
\hline & MS-HA & $\mathrm{MR} / \mathrm{K}-\mathrm{HA}$ & MR/P-HA & Thick & Thin \\
\hline NCIB 11460 & - & + & - & $-/(+)$ & +++ \\
\hline NCTC 9735 & + & - & - & $-/(+)$ & +++ \\
\hline NCTC 10006 & + & - & + & ++ & +++ \\
\hline NCTC10336 & + & - & + & ++ & +++ \\
\hline BR6 & + & - & + & ++ & +++ \\
\hline PADG 1.79 & + & - & + & ++ & +++ \\
\hline PADG 1.81 & + & - & + & $(+)$ & +++ \\
\hline PADG 2.77 & + & - & + & $(+)$ & +++ \\
\hline PADG $2 \cdot 81$ & + & - & + & $(+)$ & +++ \\
\hline PADG 4.81 & + & - & + & + & +++ \\
\hline
\end{tabular}

* NCIB = National Collection of Industrial Bacteria, Aberdeen; NCTC $=$ National Collection of Type Cultures, Central Public Health Laboratory, Colindale, London; $\mathrm{BR}=\mathrm{Mr}$ B. Reid, API Laboratory Products Ltd, Basingstoke; PADG = Dr P. A. D. Grimont, Service des Entérobactéries, Unité INSERM, Institute Pasteur, Paris, France.

$\dagger$ For description of HAs, see Duguid and Old (1980).

$\ddagger$ In haemagglutinating cultures examined, the percentage of bacteria bearing (thick or thin) fimbriae was:,$- 0 ;(+),<1 ;+, 8-10 ;++, 20-40 ;+++,>60$. 
Electronmicroscopy. Bacterial preparations were negatively stained with uranyl acetate $(0.3 \% \mathrm{w} / \mathrm{v} ; \mathrm{pH} 4.6)$ by methods described elsewhere (Adegbola and Old, 1982; Old, Adegbola and Scott, 1983). Grids were examined with a Jeol 100CX microscope and photomicrographs taken of different kinds of fimbriae observed on bacteria in different cultures. Bacteria were also stained, as described above, after interaction with different fimbrial antisera. The procedure for these immunoelectronmicroscopy (IEM) tests has been detailed elsewhere (Adegbola and Old, 1983; Old and Adegbola, 1984).

\section{RESULTS}

\section{Haemagglutinins and fimbriae}

Each of the 10 strains of $E$. aerogenes examined formed haemagglutinins and fimbriae (table I). Strain NCIB1 1460 was unusual among the strains in that it alone produced MR/K-HA. Like other Klebsielleae, strain NCIB11460 produced $\mathrm{MR} / \mathrm{K}-\mathrm{HA}$ optimally in cultures grown in broth at $30^{\circ} \mathrm{C}$ (HP values of $400-1600$ in tests with tanned erythrocytes of oxen). Thin, non-channelled fimbriae of external diameter c. $4 \mathrm{~nm}$ were observed on $>60 \%$ of the bacteria in $\mathrm{MR} / \mathrm{K}-\mathrm{HA}^{+}$cultures of that strain (table I).

E. aerogenes strain NCTC9735 produced MS-HA only (table I). Production of MS-HA was most marked with serial broth culture and occurred at all growth temperatures tested $\left(20^{\circ}, 30^{\circ}\right.$ and $\left.37^{\circ} \mathrm{C}\right)$, This strain showed the pattern of haemagglutination characteristic of other $\mathrm{MS}^{-\mathrm{HA}^{+}}$enterobacteria with fresh erythrocytes of different species (see Duguid and Old, 1980). Electronmicroscopy revealed the presence of thin, non-channelled fimbriae of external diameter c. $4 \mathrm{~nm}$ on $>60 \%$ of the bacteria in MS-HA ${ }^{+}$cultures of strain NCTC 9735.

Each of the other eight strains formed both MS-HA and MR/P-HA (table I). The MR/P-HA activities, demonstrable with fresh, untanned erythrocytes in the presence of D-mannose, were: strain PADG 4.81 agglutinated erythrocytes of guinea pig, horse and ox, and the other seven strains agglutinated erythrocytes of guinea pig and horse.

Because fresh ox erythrocytes were agglutinated by strain PADG $4 \cdot 81$, that species of erythrocyte when tanned could not be used to demonstrate MR/K-HA activity (see Duguid and Old, 1980). However, strain PADG 4.81 did not agglutinate tanned sheep erythrocytes (a species not agglutinated when fresh) and, hence, was MR/K-HA- . The other seven MS-HA ${ }^{+}, \mathrm{MR} / \mathrm{P}-\mathrm{HA}^{+}$strains neither agglutinated fresh ox erythrocytes nor gave the strong, immediate clumping of tanned ox erythrocytes that is characteristic of $\mathrm{MR} / \mathrm{K}-\mathrm{HA}^{+}$strains.

Strain PADG 4.81 was studied in some detail because, unlike the other seven MS-HA ${ }^{+}, \mathrm{MR} / \mathrm{P}-\mathrm{HA}^{+}$strains, it formed MS-HA and MR/P-HA poorly, or not at all, at $37^{\circ} \mathrm{C}$ but well at $20^{\circ}$ and $30^{\circ} \mathrm{C}$ (table II). Electronmicroscopy of cultures of strain PADG 4.81 revealed that the percentage of bacteria bearing thick, channelled fimbriae was low $(8-10 \%)$ and constant at all three growth temperatures. On the other hand, the percentage of bacteria bearing thin, nonchannelled fimbriae increased from $1 \%$ at $37^{\circ} \mathrm{C}$ to $>60^{\circ} \%$ at $20^{\circ}$ or $30^{\circ} \mathrm{C}$ (table II). Any association between these thin fimbriae and either of the haemagglutinins was not established, however, because of our inability to obtain cultures which were phenotypically $\mathrm{MS}_{-} \mathrm{HA}^{+}$and $\mathrm{MR} / \mathrm{P}-\mathrm{HA}^{-}$or $\mathrm{MS}-\mathrm{HA}^{-}$ and MR/P-HA ${ }^{+}$. 
TABLE II

The production of haemagglutinins and fimbriae by E. aerogenes strain PADG $4 \cdot 81$ in broth cultures at different temperatures

\begin{tabular}{|c|c|c|c|c|}
\hline \multirow{2}{*}{$\begin{array}{l}\text { Growth } \\
\text { temperature } \\
\left({ }^{\circ} \mathrm{C}\right)\end{array}$} & \multicolumn{2}{|c|}{ Production* of } & \multicolumn{2}{|c|}{$\begin{array}{l}\text { Percentage of bacteria } \\
\text { in haemagglutinating } \\
\text { culture with }\end{array}$} \\
\hline & MS-HA & MR/P-HA & $\begin{array}{c}\text { thick } \\
\text { fimbriae }\end{array}$ & $\begin{array}{l}\text { thin } \\
\text { fimbriae }\end{array}$ \\
\hline $\begin{array}{l}37 \\
30 \\
20\end{array}$ & $\begin{array}{c}0 \\
+++ \\
+++\end{array}$ & $\begin{array}{c}+ \\
+++ \\
+++\end{array}$ & $\begin{array}{l}8-10 \\
8-10 \\
8-10\end{array}$ & $\begin{array}{c}1 \\
60-80 \\
60-80\end{array}$ \\
\hline
\end{tabular}

* Relative amounts of HA present: $0=$ none; $+=$ trace; $+++=$ large.

The other seven MS-HA ${ }^{+}, \mathrm{MR} / \mathrm{P}-\mathrm{HA}^{+}$strains formed both haemagglutinins at all three growth temperatures tested. In these MS-HA ${ }^{+}, \mathrm{MR} / \mathrm{P}-\mathrm{HA}^{+}$cultures, c. $60 \%$ of the bacteria bore thin fimbriae. However, the percentage of bacteria bearing thick channelled fimbriae was never $>1 \%$ for some strains and yet often as high as $20-40 \%$ for other strains (figure, a). Furthermore, thick fimbriae, though not generally observed on bacteria from most haemagglutinating cultures of strains NCIB11460 (MR/K-HA only) or NCTC9735 (MS-HA only), were sometimes present in small numbers on $<1 \%$ of the bacteria in occasional cultures (table I).

\section{Immunoelectronmicroscopy}

The thick, channelled fimbriae formed by strains of $E$. aerogenes, including those formed infrequently by strains NCIB11460 and NCTC9735, were strongly coated $(+++)$ with antibody in IEM tests with type-1 fimbrial antiserum prepared against $K$. pneumoniae ss. aerogenes strain K55/1 (table III; figure, b) but not with type-1 fimbrial antiserum against $E$. cloacae strain O35 (data not shown).

Each strain formed thin fimbriae among which there seemed to be two serological groups. First, the thin fimbriae of E. aerogenes strain NCIB1 1460 were coated strongly $(+++)$ in IEM tests with type-3 fimbrial antisera prepared against $K$. oxytoca strain K70/1 and $E$. aerogenes strain NCIB 1460 (table III). Second, the thin fimbriae of the other nine strains were coated strongly $(+++)$ in IEM tests (figure, c) with fimbrial antisera against $E$. aerogenes strains NCTC9735 and NCTC10336 that formed thin fimbriae (table III). However, after the fimbrial antiserum against strain NCTC10336 had been absorbed with MS-HA ${ }^{+}$cultures of the (thin) fimbriate strain NCTC9735, it did not coat the thin fimbriae of the latter group of nine strains $(\dagger$, table III).

Thick fimbriae did not react in IEM tests with fimbrial antisera against thin fimbriae and, conversely, thin fimbriae were not coated with fimbrial antisera against thick fimbriae.

\section{Discussion}

Previous IEM studies of strains of Enterobacter and Klebsiella species indicated (i) that the thick, channelled (type-1) fimbriae associated with MS-HA belonged to three 

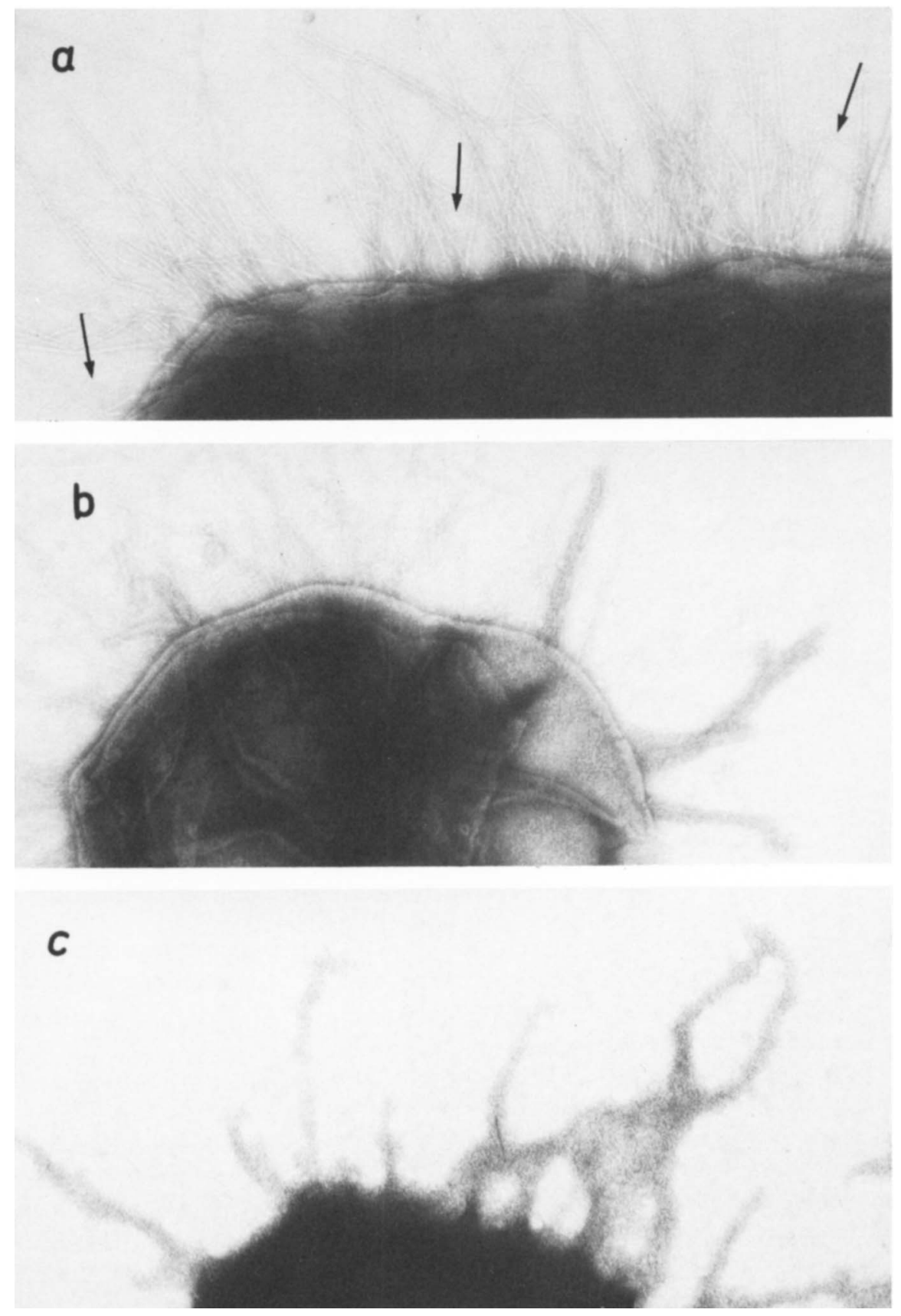

FIG.-Electronmicrographs of fimbriate E. aerogenes from haemagglutinating broth cultures: (a) strain NCTC10336 with many thick, channelled fimbriae and thin, nonchannelled fimbriae (arrowed); (b) strain PADG 1.79 after treatment with type-1 fimbrial antiserum against $K$. pneumoniae ss. aerogenes strain K55/1, with few thick fimbriae coated $(+++)$ and many thin fimbriae uncoated; (c) strain NCTC9735, after treatment with fimbrial antiserum against $E$. aerogenes strain NCTC9735 with thin fimbriae coated $(+++)$ and no fimbriae uncoated. All stained with uranyl acetate. $\times 60000$. 
TABLE III

Antibody coating of fimbriae of E. aerogenes

\begin{tabular}{|c|c|c|c|c|c|}
\hline \multirow{3}{*}{$\begin{array}{l}\text { Haemagglutinating } \\
\text { culture of } \\
\text { E. aerogenes } \\
\text { strain no. }\end{array}$} & \multicolumn{5}{|c|}{$\begin{array}{l}\text { Degree of antibody coating of fimbriae of stated type in } \\
\text { IEM tests with fimbrial* antiserum prepared against }\end{array}$} \\
\hline & $\begin{array}{l}\text { K. pneumoniae } \\
\text { ss. aerogenes } \\
\mathrm{K} 55 / 1\end{array}$ & $\begin{array}{l}\text { K. oxytoca } \\
\text { K } 70 / 1\end{array}$ & $\begin{array}{l}\text { E. aerogenes } \\
\text { NCIB } 11460\end{array}$ & $\begin{array}{l}\text { E. aerogenes } \\
\text { NCTC } 9735\end{array}$ & $\begin{array}{l}\text { E. aerogenes } \\
\text { NCTC10336† }\end{array}$ \\
\hline & Thick fimbriaet & & Thin & fimbriae $\ddagger$ & \\
\hline $\begin{array}{l}\text { NCIB } 11460 \\
\text { NCTC } 9735 \\
\text { NCTC } 10006 \\
\text { NCTC } 10336 \\
\text { BR6 } \\
\text { PADG } 1.79 \\
\text { PADG } 1.81 \\
\text { PADG } 2 \cdot 77 \\
\text { PADG } 2 \cdot 81 \\
\text { PADG } 4.81\end{array}$ & $\begin{array}{l}+++ \\
+++ \\
+++ \\
+++ \\
+++ \\
+++ \\
+++ \\
+++ \\
+++ \\
+++\end{array}$ & $\begin{array}{c}++ \\
0 \\
0 \\
0 \\
0 \\
0 \\
0 \\
0 \\
0 \\
0\end{array}$ & $\begin{array}{c}++ \\
0 \\
0 \\
0 \\
0 \\
0 \\
0 \\
0 \\
0 \\
0\end{array}$ & $\begin{array}{c}0 \\
+++ \\
+++ \\
+++ \\
+++ \\
+++ \\
+++ \\
+++ \\
+++ \\
+++\end{array}$ & $\begin{array}{c}0 \\
+++ \\
+++ \\
+++ \\
+++ \\
+++ \\
+++ \\
+++ \\
+++ \\
+++\end{array}$ \\
\hline
\end{tabular}

* K. pneumoniae ss. aerogenes strain K55/1 and $K$. oxytoca strain K $70 / 1$ produce, respectively, type-1 and type-3 fimbriae only; for fimbriae produced by strains of $E$. aerogenes, see table I.

$\dagger$ Thin fimbriae were not coated with this antiserum after absorption with MS-HA ${ }^{+}$cultures of $E$. aerogenes strain NCTC9735.

$\ddagger$ For percentage of bacteria in typical $\mathrm{HA}^{+}$cultures bearing fimbriae of stated type, see table I.

$0=$ no coating; $+++=$ strong coating.

major antigenic groups containing strains of (a) $K$. pneumoniae ss. aerogenes, $K$. pneumoniae ss. pneumoniae, $K$. oxytoca, $K$. planticola, $K$. terrigena and $K$. trevisani; (b) $E$. amnigenus, E. cloacae and E. sakazaki; (c) E. intermedium; (ii) that the thin, nonchannelled (type-3) fimbriae associated with $\mathrm{MR} / \mathrm{K}-\mathrm{HA}$ belonged to two major antigenic groups containing strains of (d) $K$. pneumoniae ss. aerogenes, $K$. oxytoca, $K$. planticola, K. terrigena, K. trevisani and E. gergoviae; (e) E. intermedium; and (iii) that there were no major cross-reactions revealed between type- 1 and type- 3 fimbriae (Adegbola and Old, 1983; Old and Adegbola, 1983 and 1984).

The few strains of E. aerogenes examined in these earlier studies were, however, not readily accommodated in any of the above groupings. This more detailed study was undertaken, therefore, with a view to clarifying the position of E. aerogenes with regard to its production of haemagglutinins and fimbriae.

In most strains of Enterobacteriaceae, the production of MS-HA is correlated with the presence of thick channelled (type-1) fimbriae (Duguid and Old, 1980), but MS-HA activity in strains of $E$. aerogenes is apparently associated with thin fimbriae; thus, strain NCTC9735 produced MS-HA only and almost invariably formed thin fimbriae only. These thin fimbriae were demonstrated on all nine $\mathrm{MS}^{-\mathrm{HA}^{+}}$strains of $E$. aerogenes and were shown by IEM tests to be unlike those of many other species of enterobacteria examined and were apparently species-specific (D. C. Old and R. A. Adegbola, unpublished results). Each of these nine strains also formed thick fimbriae which were coated with type- 1 fimbrial antiserum against $K$. penumoniae ss. aerogenes but not with that of $E$. cloacae. There was, however, no correlation between the numbers of these thick fimbriae and the strength of MS-HA activity as shown, for example, by the finding that $c .8-10 \%$ of the bacteria from both $\mathrm{MS}^{-} \mathrm{HA}^{+}$and MS-HA- ${ }^{-}$cultures of strain PADG 4.81 bore these thick, type 1-like fimbriae. If, as 
seems likely, these thick fimbriae are not principally associated with MS-HA activity in E. aerogenes, they may be mutant forms of type-1 fimbriae, serologically like the type-1 fimbriae of Klebsiella yet deficient in haemagglutinating activity, i.e., analogous to the non-haemagglutinating type-2 fimbriae of Salmonella (Old and Payne, 1971) and the type-6 fimbriae of K. ozaenae (Old and Adegbola, 1984).

Eight of the nine MS-HA ${ }^{+}$strains of E. aerogenes also formed MR/P-HA. We considered the possibility that there might be two kinds of thin fimbriae produced by $E$. aerogenes, the one associated with MS-HA and the other with MR/P-HA. Because IEM tests had proved successful in distinguishing different kinds of thin fimbriae on multi-haemagglutinating strains of Serratia (Adegbola and Old, 1982; Old et al., 1983) we employed that technique with fimbrial antisera prepared against strains NCTC9735 (MS-HA only) and NCTC10336 (MS-HA and MR/P-HA). Each antiserum coated all thin fimbriae on bacteria from MS-HA ${ }^{+}, \mathrm{MR} / \mathrm{P}-\mathrm{HA}^{+}$cultures of the eight strains forming both haemagglutinins. Had these bacteria possessed two kinds of serologically distinct thin fimbriae, some thin fimbriae would have been coated and others uncoated in tests with antiserum NCTC9735. After absorption of antiserum against strain NCTC10336 (MS-HA ${ }^{+}, \mathrm{MR} / \mathrm{P}-\mathrm{HA}^{+}$) with dense suspensions of strain NCTC9735, a procedure which should have rendered that antiserum pure with respect to MR/P-HA, it did not coat any thin fimbriae on bacteria from MS-HA ${ }^{+}$cultures of strains of $E$. aerogenes. Thus, although we were unable to derive phenotypically MS- $\mathrm{HA}^{-}$, $\mathrm{MR} / \mathrm{P}-\mathrm{HA}^{+}$cultures of these eight strains, the present evidence suggests that the MR/P-HA of E aerogenes is non-fimbrial. That being so, strain NCTC9735 differs from the other eight MS-HA ${ }^{+}$strains only in its inability to form MR/P-HA.

The only strains of Enterobacter that have MR/P-HA activities are those of $E$. aerogenes. Production of $\mathrm{MR} / \mathrm{P}-\mathrm{HA}$, though common among a majority of haemagglutinating strains of Klebsiella, (agglutination of erythrocytes of fowl only), was never found independently of MR/K-HA and is thought to be associated with a modified kind of type- 3 fimbriae in MR/P-HA ${ }^{+}$Klebsiella strains (Adegbola and Old, 1983; Adegbola, Old and Aleksić, 1983; Old and Adegbola, 1984). Thus, the MR/P-HAs of Klebsiella and E. aerogenes are different.

Species of Enterobacter other than E. gergoviae and E. intermedium did not form $\mathrm{MR} / \mathrm{K}-\mathrm{HA}$; in IEM tests the type-3 fimbriae of $E$. gergoviae were antigenically like those of Klebsiella spp. whereas those of E. intermedium were antigenically like those of Serratia spp. (Adegbola and Old, 1983; Old and Adegbola, 1984). It was, therefore, of interest to find that $E$. aerogenes strain NCIB1 1460 also produced $\mathrm{MR} / \mathrm{K}-\mathrm{HA}$ and Klebsiella-like, type-3 fimbriae. Although two other strains (NCIB10917, NCIB10918) received as $E$. aerogenes were previously reported as forming MR/K-HA and type-3 fimbriae (Adegbola and Old, 1983), these strains have since been identified as $K$. pneumoniae ss. aerogenes (D. C. Old, unpublished results; Professor L. Le Minor, personal communication). Accordingly, the true identity of strain NCIB11460 is of critical importance.

It is notoriously difficult to differentiate $E$. aerogenes and $K$. pneumoniae ss. aerogenes though tests for motility, production of urease and ornithine decarboxylase are generally helpful (Brenner, Steigerwalt and Fanning, 1972; Sakazaki et al., 1976). The most important character against identification of strain NCIB11460 as $K$. pneumoniae ss. aerogenes was decarboxylation of ornithine; those against its identification as E. aerogenes were non-motility and urease production. Nevertheless, by 
conventional means and with the use of kits such as API $20 \mathrm{E}$, this strain was identified as $E$. aerogenes. Furthermore, it grew on meta-hydroxybenzoate as sole carbon source and, when grown in histidine-containing medium (Enjalbert et al., 1979) at $37^{\circ} \mathrm{C}$, formed histamine detectable by the method of Eggerth, Littwin and Deutsch (1939). These latter two properties are considered characteristic of E. aerogenes (Richard, 1977; Enjalbert et al., 1979). However, strain NCIB11460 was not satisfactorily identified by computer-assisted methods and behaved like a strain with properties intermediate between those of $E$. aerogenes and $K$. pneumoniae ss. aerogenes $(\mathrm{Mr} \mathrm{B}$. Holmes, personal communication). Therefore, the identification of this problematic strain by other techniques such as DNA-DNA hybridisation should prove of interest.

The taxonomic position of E. aerogenes itself has long been contentious (Bascomb et al., 1971; Brenner et al., 1972). Data from numerical-taxonomy studies, however, have indicated that $E$. aerogenes might be transferred to the genus Klebsiella as $K$. mobilis (Bascomb et al., 1971), a suggestion supported by data from DNA-DNA hybridisation studies (Izard et al., 1980) and by similarities in the capsular antigens (Richard, 1977) and the electrophoretic patterns of the esterases (Goullet, 1980) of $E$. aerogenes and $K$. pneumoniae. Whilst this study has revealed important differences in the fimbriae and haemagglutinins of $E$. aerogenes and $K$. pneumoniae ss. aerogenes of potential importance for their differentiation, it has provided little evidence to support either the transfer of E. aerogenes to Klebsiella as K. mobilis or its retention as a species of Enterobacter. Thus, the relationship of the fimbriae of $E$. aerogenes to those of other species of Enterobacter and Klebsiella remains as difficult to establish as the taxonomic position of $E$. aerogenes in the tribe Klebsielleae.

We thank Dr P. A. D. Grimont and Mr B. Reid for the gift of strains and Mr B. Holmes for valuable help regarding the identification of strain NCIBI 1460. R.A.A., an Oyo State scholar on study leave from Lagos University Teaching Hospital, Nigeria thanks the C.V.C.P. (U.K.) for an ORS award.

\section{REFERENCES}

Adegbola R A, Old D C 1982 New fimbrial hemagglutinin in Serratia species. Infection and Immunity 38:306-315.

Adegbola R A, Old D C 1983 Fimbrial haemagglutinins in Enterobacter species. Journal of General Microbiology 129:2175-2180.

Adegbola R A, Old D C, Aleksić S 1983 Rare MR/K-like haemagglutinins (and type 3-like fimbriae) of Salmonella strains. FEMS Microbiology Letters 19:233-238.

Bascomb S, Lapage S P, Willcox W R, Curtis M A 1971 Numerical classification of the tribe Klebsielleae. Journal of General Microbiology 66:279-295.

Brenner D J, Steigerwalt A G, Fanning G R 1972 Differentiation of Enterobacter aerogenes from Klebsiellae by deoxyribonucleic acid reassociation. International Journal of Systematic Bacteriology 22:193-200.

Duguid J P 1959 Fimbriae and adhesive properties in Klebsiella strains. Journal of General Microbiology 21:271-286.

Duguid J P, Old D C 1980 Adhesive properties of Enterobacteriaceae. In: Beachey E H (ed) Bacterial adherence (Receptors and recognition, series B, vol 6). Chapman and Hall, London, pp 185-217.

Edwards P R, Ewing W H 1972 Identification of Enterobacteriaceae, 3rd edn. Burgess Publishing Co., Minneapolis.

Eggerth A H, Littwin R J, Deutsch J V 1939 The determination of histamine in bacterial cultures. Journal of Bacteriology 37:187-203. 
Enjalbert F, Richard C, Attisso M, Crémieux A 1979 Intérêt de la recherche de l'histidine-décarboxylase (HDC) chez les espèces du groupe Klebsiella-Enterobacter-Serratia. Annales de Microbiologie 130A:385-388.

Goullet P 1980 Distinctive electrophoretic patterns of esterases from Klebsiella pneumoniae, $K$. oxytoca, Enterobacter aerogenes and E. gergoviae. Journal of General Microbiology 117:483-491.

Izard D, Gavini F, Trinel P A, Krubwa F, Leclerc H 1980 Contribution of DNA-DNA hybridization to the transfer of Enterobacter aerogenes to the genus Klebsiella as K. mobilis. Zentralblatt für Bakteriologie, Mikrobiologie und Hygiene, I Abt. Orig. C 1:257-263.

Old D C, Adegbola R A 1982 Haemagglutinins and fimbriae of Morganella, Proteus and Providencia. Journal of Medical Microbiology 15:551-56̨4.

Old D C, Adegbola R A 1983 A new mannose-resistant haemagglutinin in Klebsiella. Journal of Applied Bacteriology 55:165-172.

Old D C, Adegbola R A 1984 A comparative immunoelectronmicroscopical study of fimbriae of Enterobacter and Klebsiella. Systematic and Applied Microbiology 5:157-168.

Old D C, Adegbola R, Scott S S 1983 Multiple fimbrial haemagglutinins in Serratia species. Medical Microbiology and Immunology 172:107-115.

Old D C, Payne S B 1971 Antigens of the type-2 fimbriae of salmonellae: "cross-reacting material' (CRM) of type-1 fimbriae. Journal of Medical Microbiology 4:215-225.

Richard C 1977 Présence chez Enterobacter aerogenes d'antigènes capsulaires apparentés à ceux de Klebsiella. Intérêt de l'utilisation du métahydroxybenzoate dans le diagnostic différentiel E. aerogenes-K. pneumoniae. Annales de Microbiologie 128A:289-295.

Sakazaki R, Tamura K, Johnson R, Colwell R R 1976 Taxonomy of some recently described species in the family Enterobacteriaceae. International Journal of Systematic Bacteriology 26:158-179. 